\title{
Decomposition of Gender Differentials in Agricultural Productivity: The Case Aira District in West Wollega Zone Oromia National Regional State Ethiopia
}

\author{
Bacha Gebissa \\ Department of Agricultural Economics, Wollega University, Shambu, Ethiopia
}

\begin{abstract}
The research is financed by Ministry of Education of Ethiopia in general and Wollega University particularly Abstract

This study focused on decomposion of gender differential on agricultural productivity. The agricultural productivity difference between male and female headed households was about $\mathbf{5 7 . 1 8 \%}$ in the study area. On the other hand, if female headed households had equal access to the inputs as male headed households, gross value of the output would be higher by $18.82 \%$ for female headed households. This may suggest that female headed households would have been more productive than male headed households if they had equal access to inputs as male headed households. Thus accessing female headed households to inputs that increase the productivity of land, labour utilization, usage of herbicide; and introducing technologies that reduce the time and energy of women is essential to improve the agricultural productivity of women and the society as a whole.
\end{abstract}

Keywords: Aira, Decomposition Model, Gender, West Wollega

DOI: $10.7176 /$ JAAS/60-01

Publication date: January $31^{\text {st }} 2020$

\section{INRODUCTION}

Gender differences in agricultural productivity in developing countries are observed mainly in the access to and use of agricultural inputs, tenure security, and related investments in land and improved technologies, market and credit access, human and physical capital, and informal and institutional constraints. These factors explain the difference in agricultural productivity between male-managed plots and female-managed plots (Olakojo, 2017).

Most estimates of male-female differences in technical efficiency from production function studies show that male and female farmers are equally efficient farm managers, controlling for levels of inputs and human capital (Addison et al,2016). It is often argued that women's lower levels of human and physical capital result in lower productivity or inability to respond to economic incentives. Much of the evidence cited to support this argument comes from agriculture. Yet, the measurement of differences in agricultural productivity between men and women is fraught with conceptual and methodological difficulties. These arise from the difficulty of defining appropriate measures of productivity in different farming systems, omission of individual characteristics in attempts to measure productivity differences by sex, and the lack of clarity regarding the measurement of sex and gender differences.

An evaluation of male-female productivity differences should ideally be based on estimates of total factor productivity, in which an index of output is divided by an index of inputs, aggregated over all types of outputs and inputs, respectively. Lack of gender-differentiated data on inputs and outputs, however, has prevented the use of this approach. Existing studies therefore use partial productivity measures, such as yield and labor productivity. These partial measures of productivity are complicated by differences in farming systems and social and cultural institutions. It is feasible to estimate technical efficiency differences between male and female farmers in farming systems where men and women manage separate plots, as in many African societies (Mukasa and Salami, 2016).

That is, women farmers would be expected to have lower productivity simply because they are female, not because they have fewer resources. Such an error would be unfortunate because the accurate diagnosis of sources of productivity differences, if they exist, is important in order to identify appropriate policy interventions for increasing women's productivity and welfare. The inadequate specification of individual farmer characteristics contributes further to the confusion between "sex" and "gender" as a source of productivity differences. Sex differences are due to innate biological differences between men and women. Gender differences, on the other hand, arise from the socially constructed relationship between men and women. These differences affect the distribution of resources and responsibilities between men and women, and are shaped by ideological, religious, ethnic, economic, and cultural determinants (Oakley, 2016).

Ethiopia is one of most populated country with 112.78 million inhabitants distributed along a one million square kilometer land-locked area (Worldometers, 2019). Women in the agricultural sector in Ethiopia already face many socio-economic, educational and traditional legal obstacles in realizing benefits of their effort (Tesfaye and Desta, 2017). The situation in the study area, Aira district, is not different from Ethiopian case. The district is one of the highly populated areas in West Wollega Zone where population density is about 217 persons per $\mathrm{Km}^{2}$ (CSA, 2019). As the result, farm size is so small to produce sufficient food to the population and the number of 
female headed households is also increasing from time to time since death of husband, divorced problem and males are migrating to other areas in search of better employment leaving behind their wives and children. Thus, females would take over the position of their husband in addition to their routine household management. Therefore, it is essential to study the productivity of female headed households in agricultural sector as compared with their male counterparts in the area where gender dis-aggregated information in this aspect is missing.

\section{RESEARCH METHODOLOGY}

\subsection{Description of the study area}

Aira district is one of the twenty three districts found in West Wollega zone of Oromiya Regional State. It is located at a distance of $532 \mathrm{~km}$ from Finfinne, the capital city of the country. The capital town of the zone is Gimbi which is $94 \mathrm{~km}$ from the district. It is bounded by Gulliso in the north, Yubdo in southeast and Kelem Wollega Zone in the south and west. Aira is the administrative center.

Currently the total population of the district is 60,971 out of which females account for $46.84 \%$. The community in the district comprises of a total of 7719 households $(11.92 \%$ female headed households). The average family size is estimated to be 6 persons per household and the average population density is 217 per $\mathrm{km} 2$.The population of Aira district is almost exclusively Oromo constituting $99 \%$ of the population. The rest $1 \%$ of the ethnic groups are Guraghe and Amhara. The religions of the district are Orthodox Christian $(31.98 \%)$, Protestant (59.84\%), Muslim (5.59\%) and traditional beliefs (1.19\%) of the population (CSA, 2019 of the Aira district).

Agriculture is the dominant economic activity engaging $90 \%$ of the labour force (CSA, 2019 of the district). Crop production is dependent on rainfall and the major crops produced in the area according to their importance are Maize (26\% of total area cultivated), Millet (24\%), sorghum (10\%), Teff $(6 \%)$, barely (4\%) and pulses (horse bean, field pea and lentil covering about $11 \%$ of the total cultivated area). Coffee is one of most cash crops grown in the woreda and the most source of income for the population of the woreda. Productivity of these crops is below the national average due to poor fertility of soil, poor agronomic practices and use of low level of agricultural inputs.

\subsection{Type, Source of Data and Methods of Data Collection}

Both qualitative and quantitative data were collected from primary and secondary sources. The qualitative data were collected through focus group discussion and participatory observation. The quantitative data were gathered by using of structured questionnaire.

\subsection{Sampling Method and Sample Size Determination}

This study employed probability sampling procedure to draw a representative sample. Two stage sampling procedure were used to select sample households. In the first stage, about 6 kebeles were selected randomly from 20 Kebeles found in the district. In the second stage from these 6 Kebeles 60 male and 60 female headed households are randomly selected. The total sample from each kebeles, male and female headed households is determined by fifty (50) to fifty (50) ratios respectively due to the lower number of female headed households in the data to define the proportion. Probability proportional to sample size was employed to select the total of sampled households' farmers. Hence, a total of 120 households were selected (table 1). The sample size was determined by using the formula given by Yamane (1967: 886) as follow:

$$
n=\frac{N}{1+N\left(e^{2}\right)}
$$

Where:

$n$-Represents sample size

$N$-Represents total number Male headed and Female Headed

$e$-Represents the desired level of precision (taking 9\%) 
Table 1. Distribution of sample households by Kebeles and sex of household head

\begin{tabular}{|c|c|c|c|c|c|c|}
\hline \multirow[t]{2}{*}{ Kebele } & \multicolumn{3}{|c|}{$\begin{array}{l}\text { Total number of } \mathrm{MHH} \text { and } \mathrm{FHH} \text { in the } \\
\text { selected kebeles }\end{array}$} & \multicolumn{2}{|c|}{$\overline{\text { Sample }}$} & \multirow[b]{2}{*}{ Total } \\
\hline & Male Headed & Female Headed & Total & Male Headed & Female Headed & \\
\hline Abayani Aira & 317 & 174 & 491 & 10 & 8 & 18 \\
\hline Lalisa Aira & 552 & 225 & 577 & 11 & 7 & 18 \\
\hline Wayu Koli & 415 & 193 & 608 & 11 & 9 & 20 \\
\hline Lalo Aira & 534 & 223 & 757 & 13 & 11 & 24 \\
\hline Degaga Aira & 385 & 182 & 567 & 11 & 8 & 19 \\
\hline Gudina Aira & 424 & 223 & 647 & 12 & 9 & 21 \\
\hline Total & 3027 & 620 & 3647 & 60 & 60 & 120 \\
\hline
\end{tabular}

Source: Administration Office Baseline Survey and Survey Sampling (2019)

\subsection{Methods of Data Analysis}

Oaxaca-Blinder decomposition model of the productivity differential between male and female farmers was used to decompose the productivity difference (Oaxaca, 1973). Although this approach is to decompose the wage gap, it can also be applied to decompose productivity difference between, say, men and women farmers (Shambel, 2013; Tadele and Mahendran, 2015). The decomposition model adopted was presented as follows:

$$
\ln \left(\frac{Y_{m}}{Y_{f}}\right)=\left\lceil\left(B_{i m}-B_{i f}\right) \ln X_{i f}\right\rceil+\left[B_{1 f} \ln \left(\frac{X_{i m}}{X_{i f}}\right)\right]
$$

Where:-

$\mathrm{Y}_{\mathrm{m}}$ and $\mathrm{Y}_{\mathrm{f}}$ represent mean output (Geometric mean) of males and females respectively

$X_{i m}$ and $X_{\text {if }}$ are geometric mean levels of inputs of male and female

$B_{\text {im }}$ and $B_{\text {if }}$ are estimate of output elasticities of male and female headed households as defined earlier.

The model decomposes the overall average male-female output gap into the portion due to differences in the technical efficiency and the portion attributable to differences in input endowments. In other words, the first bracketed expression on the right hand side is a measure of change in output due to shift in output elasticities of the production functions. The second bracketed term is a measure of difference in output due to difference in volume of input use per hectare.

\section{RESULTS AND DISCUSSION}

\subsection{Source of productivity difference}

This section presents estimates of the agricultural productivity differences between male and female headed households using decomposition model. As discussed in section 2.4, this model is helpful to measure the percentage contribution of the different to agricultural productivity difference between male and female headed households. This method allows distinguishing the productivity difference that can be explained by differences in household endowments and differences in the efficiency of these endowments. In addition to the estimates of production functions, the decomposition analysis requires the geometric mean values of different inputs and output. Table 2 presents geometric mean values of various inputs and output in both $\mathrm{MHH}$ and FHH. The geometric mean of output and input endowments were computed from the explanatory variable before converting to natural logaresim since geometric mean does not compute negative values in the data. It is observed that the inputs used by $\mathrm{MHH}$ were higher as compared to $\mathrm{FHH}$ for all the explanatory variables used in the model. 
Table 2. Geometric mean of dependent and explanatory variables in the model

\begin{tabular}{lcc}
\hline \hline Variables & Male headed & Female headed \\
\hline Livestock holding in TLU & 2.98 & 3.4 \\
Land used(ha) & 1.379 & 0.8912 \\
Educational level (in years of schooling) & 0.001 & 0.001 \\
Inorganic fertilizer used (Kg) & 75.12 & 64.65 \\
Herbicides used (Lit) & 0.0001 & 0.01 \\
Labour used (Man-days) & 85.397 & 78.04 \\
Amount of credit used (birr) & 3071.42 & 3070.33 \\
Improved seed used on average ( kg) & 0.0001 & 0.1 \\
Number of extension contact & 32.77 & 33.27 \\
Farm experience(years) & 25.94 & 25.8 \\
Number of oxen(number) & 0.01 & 5.5 \\
Non-farm/off farm income(birr) & 1212.3 & 1211.2 \\
\hline Gross value of farm output (birr/year) & $53,471.52$ & $49,014.78$
\end{tabular}

Source: Own survey result (2019)

By following the methodology described in the section 2.4 (equation 2), the total sources of productivity difference were decomposed into output elasticities and input endowments (table 3 ).

Table 3. Decomposition of productivity difference between $\mathrm{MHH}$ and $\mathrm{FHH}$

\begin{tabular}{lcc}
\hline \hline \multirow{2}{*}{ Sources of productivity difference } & \multicolumn{2}{c}{ percentage Contribution } \\
\cline { 2 - 3 } & Due to output elasticities & Due to input endowments \\
\hline \hline Total estimated difference (57.18\%) & -18.82 & 76.02 \\
\hline Livestock holding & 8.5 & 1 \\
Land used & -1.6 & 67.5 \\
Educational level & -2.7 & 0 \\
Fertilizer used & -68.7 & 17.4 \\
Herbicides used & 83.8 & -4.6 \\
Labour used & -5.6 & 9.8 \\
Amount of credit used & -3.8 & 0.04 \\
Improved seed used on average & -51.3 & -0.69 \\
Number of extension contact & -4.5 & -1.5 \\
Farm experience & -7.2 & 0.5 \\
Number of oxen & 33.7 & -1.1 \\
Non-farm/off farm income & 2.8 & 0.09 \\
\hline \hline
\end{tabular}

Source: Own survey (2019)

As shown in the above table it can be seen that the total productivity difference in agriculture between the two groups was about $57.18 \%$. However, they have different human capital, endowment and different access to factors and inputs as discussed in the descriptive part. Inputs use differentials accounted for $76.02 \%$. This implies that the productivity could be increased by $76.02 \%$, if the FHH could adjust their inputs to the same level of MHH. On the other hand, the difference in output elasticities was $-18.82 \%$. This indicates that productivity difference as the result of difference in output elasticities is greater for $\mathrm{MHH}$ as compared to that of FHH. The result was relatively confirmed with Tadele and Mahendran (2015) in their study of gender differences and its impact on agricultural productivity in the case of Sheko district in Benchi Maji Zone of SNNP, Ethiopia.

A comprehensive assessment of the contributions made by different inputs in the total productivity gap between male and female headed households reveals that difference in access to land use caused the biggest bound. This further indicates that if FHH could adjust their farm land to the level of MHH, they can increase their productivity by about $57.18 \%$. Hence, increasing the access of FHH to farm land could highly increase their productivity in agriculture in the study area. Descriptive results of this study also show that on average FHH had only 2.05 mean of land size while $\mathrm{MHH}$ had about 2.80 mean of land size on average, which was significant at $1 \%$ probability level $(\mathrm{t}=1.71)$. And also inorganic fertilizer, labour, livestock holding, farming experiences, Non- farm income and amount of credit use contributes difference between $\mathrm{MHH}$ and FHH made about 17.4\%, 9.8\%, 1\%, $0.5 \%, 0.09 \%$ and $0.04 \%$ productivity difference in agriculture, respectively (table 3 ).

Most researchers often argued that women's lack of access to resources results in lower productivity or inability to respond to economic incentives (Shambel, 2013; Tadele and Mahendran, 2015). Looking at the contribution made by the output elasticities or change in factor specific productivity, herbicides used is one of the variables which contribute largely to output elasticities or change in factor specific productivity difference. Which constitutes $83 \%$ to the total output difference followed by fertilizer used and improved seed in which they reduce 
the diffence in output gap by $68.7 \%$ and $51.3 \%$ respectively. Number of oxen and non-farm/off-farm income contributes output gap between $\mathrm{MHH}$ and $\mathrm{FHH}$ by $33.7 \%$ and $2.8 \%$ correspondingly.

\section{SUMMARY AND CONCLUSION}

The study examined on decomposition of gender differentials in agricultural productivity: The case of Aira District in West Wollega Zone Oromia National Regional State Ethiopia. The data used in this study were collected from $60 \mathrm{MHH}$ and $60 \mathrm{FHH}$ randomly selected from 6 Kebeles of the district. Independent t-test was used to test the differences between $\mathrm{MHH}$ and $\mathrm{FHH}$ in terms of continuous variables and $x^{2}$-test for categorical variables. Moreover, decomposion Model was estimated to measure productivity difference between MHH and FHH.

The total productivity difference in agriculture between the two groups was about $57.18 \%$. However, they have different human capital, endowment and different access to factors and inputs. Inputs use differentials accounted for $57.18 \%$. This implies that the productivity could be increased by $76.02 \%$, if the FHH could adjust their inputs to the same level of MHH. On the other hand, the difference in output elasticities was-18.82\%. This indicates that productivity difference as the result of difference in output elasticities is greater for $\mathrm{MHH}$ as compared to that of FHH.

\section{REFERENCES}

Addison, M., Ohene-Yankyera, K. and Fredua-Antoh, E., 2016. Gender role, input use and technical efficiency among rice farmers at Ahafo Ano North district in Ashanti region of Ghana. Journal of Food Security, 4(2): 27-35.

CSA (Central Statistical Agency), 2019. Agricultural sample survey: Area and production of crops, main season, Annual Report of Aira district.

Mukasa, A.N. and Salami, A.O., 2016. Gender productivity differentials among smallholder farmers in Africa: A cross-country comparison. African Development Bank Group Working Paper, 231

Oaxaca, R., 1973. Male-Female differentials in urban labour markets. International Economic Review, 14(1): 693-09.

Olakojo, S.A., 2017. Gender gap in agricultural productivity in Nigeria: A commodity level analysis. Economics of Agriculture, 64(2): 415-435.

Shambel Worku, 2013 .Gender Differential in Agricultural Production and Its Impact on Household Farm Income: The Case of Fed is District in East Hararghe, Ethiopia.

Tadele Melaku and Dr. A. Mahendran, 2015. Gender difference and its impact on agricultural productivity: The case of Sheko district in bench Maji zone of SNNP, Ethiopia”, International Journal of Current Research, 7(11): 22938-22942.

Tesfaye Abebe and Desta Mulu, 2017. The role of women in the management and utilization of home garden: The Case of Dale District, in Southern Ethiopia. Asian Journal of Plant Science and Research, 7(4):41-54.

Worldometers, 2019. World Population Prospects: Department of economic and social affairs, Population division. The 2017 Revision. Available at www.worldometrers.info info/ world-population/Ethiopia-population/).

Yamane Taro, 1967.Statistics: An introductory analysis, ${ }^{\text {nd }}$ Ed., New York: Harper and Row 